\title{
Reviewers as developmental coaches
}

\author{
Mark B. Houston ${ }^{1}$. John Hulland ${ }^{2}$
}

Published online: 2 October 2020

(C) Academy of Marketing Science 2020

As the two of us (as editors) begin putting together our third volume of the Journal of the Academy of Marketing Science (JAMS), and look ahead to a second editorial "tour of duty," we believe it is an appropriate time to reflect on our experiences to date and offer some guidance to our journal reviewers. In doing so, it is our aim to provide a fresh perspective on the reviewer's role. Our field has a long history of articles and editorials offering excellent and practical guidance on writing reviews (e.g., Bagchi et al. 2017; Lehmann and Winer 2017; Moorman et al. 2019), so rather than simply echoing this earlier advice, in what follows we use the analogy of hit song-making. We certainly encourage reviewers to abide by the best practices highlighted in the aforementioned articles, but our main objective for this editorial is to inspire reviewers to re-envision their role when evaluating manuscripts for possible publication in JAMS.

Why song-making? As music aficionados, we believe that the process of writing, refining, and recording a song demonstrated on NBC's hit show Songland can be seen as very analogous to the process of crafting, revising, and publishing a scholarly paper. In Songland, three unknown, aspiring songwriters (who survive an initial screening round) get the career-altering opportunity to pitch a song to a guest national recording artist (e.g., Martina McBride, Macklemore, Usher) who ultimately chooses one of those songs to record. The show begins with each young songwriter performing a "first look" of

Mark B. Houston

m.b.houston@tcu.edu

1 Department of Marketing, Neeley School of Business, Texas Christian University, Fort Worth, TX, USA

2 Department of Marketing, Terry College of Business, University of Georgia, Athens, GA, USA their song for a panel of experienced songwriters and the guest artist. After the panelists and artist deliberate, each songwriter is matched with one panelist "coach" with whom they collaborate to improve their song's lyrics, flow, instrumentation, musical structure, etc. The songwriters perform their revised songs, the guest artist makes their final choice, and the artist then records the song for release. Many of these songs have gone on to hit \#1 on an iTunes chart.

In nearly all cases, the constructive criticism and guidance from the panelists that the unknown songwriters receive make the revised songs better. And in many cases, the sum of the many seemingly minor changes can be magical; the songwriter's original vision and spirit shine through in a new way as aspects of the early draft that were distracting, poorly executed, or poorly fitting are pared away, refined, and improved. This process sometimes leaves "the songwriters standing there, stunned, open-mouthed with amazement as their songs transform into something bigger and grander" (Stetson 2019).

We identify three key takeaways from observing the Songland experience. First, the resulting final product is still the songwriter's song, not the panelist's. However, it has been improved - often dramatically — by the panelist's guidance. Second, without "pulling any punches" regarding weaknesses and areas in need of improvement, the panelists approach their job with the spirit of helping the song become the best it can be, and not to destroy it. Third, even with a supportive "review" process, and even if each panelist absolutely loves the song he or she works with, not every song will be successful.

These takeaways mirror what we believe to be a healthy scholarly manuscript review process, something that we currently see from time to time at JAMS but would like to foster and encourage on a more regular basis. In order for this to work, reviewers need to take the three insights we note above to heart when they evaluate papers and write their reports. So let us examine how each, in turn, applies to the review process for a manuscript submitted to JAMS. 


\section{Insights for reviewers}

\section{"We need love": It is the songwriter's song"}

First, the paper is the author's (authors') paper, and authors deserve the opportunity to try to implement their own vision. This creates a tension between reviewers and authors, one that needs to be carefully balanced: reviewers should not wrest developmental control away from authors, whereas authors must rely on the reviewers' guidance to improve their work. The most effective reviewers provide clear guidance regarding specific issues that have to be handled, but without encroaching on the author's space and becoming a micromanaging and domineering "coauthor." In other words, while they offer detailed suggestions and identify potential paths forward (often with an assessment of specific pros and cons), the best reviewers avoid generating dictatorial or dogmatic requirements. Instead, they define a problem clearly but then allow the authors to retain significant agency in how to solve the problem. The authors may make bad choices that result in the paper ultimately being rejected, but in many cases they rise to the challenge and innovate their own unique solution that effectively addresses the reviewer's core concern.

Please note that we are not advocating that reviewers make only general, abstract comments to authors. In fact, one of the biggest weaknesses that harms the effectiveness of a review is to make general appraisals (e.g., "I didn't like this section"; "I didn't find the hypotheses compelling"; "Isn't there heterogeneity?") without providing enough detail for the author to be able to respond effectively. High level appraisals are fine as topic sentences, but they should be followed up with specific examples and detail so that the issue that concerns the reviewer is clear to the author.

Once the issue is clear, the reviewer can also be very specific in terms of potential remedies. If there is a quick fix or truly only one "right way" to handle an issue, then such guidance should be provided. Even for complex and thorny issues that are less straightforward, a reviewer probably has specific recommendations in mind. However, the way these recommendations help is often not because the author follows them by rote, but because they inspire the author's creativity in crafting an even better solution.

\section{Action items for JAMS reviewers:}

- Provide enough specific detail to insure that the author fully understands your issues/concerns.

\footnotetext{
${ }^{1}$ For each of our three insights, we reference a successful song that emerged from the Songland experience. "We Need Love," featured on Songland May 28, 2019, and written by contestant Tebby Burrows, was released by artist John Legend.
}

- Provide specific recommendations for potential paths forward for the author's consideration, but acknowledge their agency/ownership in how to solve the problem.

- To keep the author-centric mindset active, good reviewers and AEs explicitly state what they like about the paper and what they see as its promising essence. ${ }^{2}$

\section{“Hurt me" / "Be nice": Do not pull any punches ${ }^{3}$}

Second, reviewers should not "pull any punches" or lower their standards; however, they should approach their task with the spirit of providing constructive criticism that will help the paper become the best it can be. A recent editor lamented that "More than $97 \%$ of reviewers' recommendations are to 'reject"' (Kumar 2016, p. 5). Whereas the vast majority of scholars who review for JAMS would agree with the ideal of being constructive, two forces conspire to too-often create an adversarial approach in which the reviewer defaults to a "screening" mindset (i.e., keeping weak papers out of JAMS) rather than using a developmental mindset.

One of these forces is simply time pressure. JAMS reviewers volunteer their time, but that time is precious and limited as talented scholars navigate multifaceted competing demands from their own research, reviewing for multiple journals, teaching and mentoring students, maintaining some level of work-life balance, etc. (and these pressures have been intensified by a global pandemic). It does not take much time to quickly identify a list of problematic aspects ("fatal flaws!") in any initial submission. It takes more time to dive deeply into a paper, truly reflect on whether flaws are fatal, and identify potential ways to mitigate aspects that detract from a paper's contribution or fail to employ sufficient rigor to support claims. Few scholars approach a review with ill-intent, but when several clear problem areas emerge within the first few minutes of a reviewer's initial read, it is very difficult to retain an open mind and a constructive spirit (e.g., "why throw effort into a paper that has 'no chance' of being published?").

The other force is a desire to uphold the standards of the discipline (to which every reviewer is subjected when they submit their own work to strong journals) and to protect the reputation of JAMS. No one wants to get a bad reputation as being a weak reviewer, but there is sometimes perverse pride gained from being too harsh (which can easily be rationalized as "having high standards"). Further, every scholar has had

\footnotetext{
${ }^{2}$ Carol Saunders (2005) describes this as the process of recognizing the hidden gem that lies within, and then helping to reveal its luster.

3 "Hurt Me," featured on Songland June 25, 2019, and written by contestant Kole, was released by artist Meghan Trainor. "Be Nice," featured on Songland, June 4, 2019, and written by contestant Adam Friedman, was released by artist will.i.am.
} 
Table 1 Key action items for being a "developmental coach"

\begin{tabular}{ll}
\hline Insights & Action items for JAMS reviewers \\
\hline It is the author's paper & - Provide enough detail to insure that the author understands your issues/concerns. \\
• Provide specific recommendations, but acknowledge the author's & agency/ownership in how to solve the problem. \\
- Explicitly state what you like about the paper and what you see as its promising \\
essence. \\
- View the reviewer role using a constructive, developmental mindset, not (only) a \\
screening mindset. \\
- Treat an author's paper with the same respect with which you hope your own papers \\
are treated. If you are time-pressed, please ask for a time extension. \\
- Identify aspects of the paper that fall short; constructive criticism, by definition, \\
requires criticism. However, be judicious with labeling a flaw as "fatal." \\
- Prioritize and organize your comments to the authors so that they can allocate their \\
time and effort toward the most-needed (and critical) improvements. \\
- Provide constructive and positive feedback to authors even if you believe their work \\
is not up to the journal's standards. \\
- Recognize that your review comments on papers that we reject at JAMS are not \\
wasted; they improve the quality of the paper wherever it is eventually published.
\end{tabular}

their own research treated unfairly or held to inappropriate or inapplicable standards by reviewers. In response, although we should be inspired to avoid misbehaving in that way when we are the reviewer, there are some meddlesome all-too-human reactions that make it feel dramatically unfair if someone else has an "easier" path to publication. Thus, despite a desire to be fair, we often end up perpetuating unfair treatment using the exact inappropriate standards that were imposed on us. As a senior marketing scholar colorfully described this phenomenon to one of us early in his career, "yeah, people in that research domain basically beat the living \%\&\#@ out of each other." At JAMS, we do our best to take a balanced view of rigor (see Houston 2019).

Finally, the best reviewers and AEs prioritize and organize their comments to help authors make meaningful progress in a revision (often 1.5 to 2.5 single-spaced pages). A review centered around a limited number of key/major concerns that are well spelled out and that have meaningful suggested plans of action associated with them is far more effective than a rambling list of items that comes across as a stream-of-consciousness generated during the reviewer's first reading of the paper. Although we encouraged specificity in the prior section, there needs to be a balance between the number of comments generated and their actionability. Identifying a list of problems while initially reading a manuscript can provide a useful starting point for a review by helping the reviewer recall important ideas; nonetheless, it should be just that - a starting point. If submitted as initially compiled, a 4-5 page list that mixes important concerns with minor tweaks is neither effective nor efficient. In such situations, authors will often spend too much time fixing minor problems and too little on properly addressing the most crucial issues.

\section{Action items for JAMS reviewers:}

- View the reviewer role using a constructive, developmental mindset, not (only) a screening mindset. You want to be the coach who helped the songwriter find their voice on the song chosen by the recording artist.

- Treat an author's paper with the same respect with which you hope your own papers are treated. If you are time-pressed, we as editors can always provide an extension so that you will have time to complete a review thoughtfully.

- Do not pull any punches in identifying areas that fall short in a paper. Constructive criticism, by definition, requires criticism. However, remembering that every initial submission falls short of being publishable, be judicious with labeling a flaw as "fatal."

- While being thorough, be sure to prioritize and organize your comments to the authors so that they can allocate their time and effort productively toward the mostneeded (and critical) improvements.

\section{“Better luck next time": Not every song wins ${ }^{4}$}

Finally, following a constructive approach does not mean that every paper will ultimately be published in JAMS. Many high-

\footnotetext{
4 "Better Luck Next Time," featured on Songland June 11, 2019, and written by contestant Darius Coleman, was released by artist Kelsea Ballerini.
} 
quality papers are submitted for review to JAMS, but all have countervailing strengths and weaknesses. As editors, we make difficult decisions about which ones offer the greatest potential contributions. Still, it is our hope that every paper that is reviewed by JAMS' dedicated reviewers and AEs will emerge from the review process as a stronger paper, wherever those papers are ultimately published. This approach raises the average quality of scholarship in our field. Many reviewers also derive some pleasure from playing a meaningful role in another person's scholarly journey; these reviewers view their task as a form of mentoring that enables an open-minded author to learn and grow as a scholar.

In making manuscript-disposition decisions, we rely on reviewers' expert insights, but do not "vote count." Further, we have to weigh the relative merits and weaknesses of any paper against the standards of JAMS and against our sense of what it takes to make a meaningful contribution in the paper's topical domain. As a result, some papers that have merit will not be accepted, whereas other papers that an individual reviewer dislikes will ultimate be published. We value the perspectives that reviewers bring to their reports, but as editors we ultimately have to make our decisions based on a wide range of factors.

\section{Action items for JAMS reviewers:}

- Provide constructive and positive feedback to authors even if you believe their work is not up to the journal's standards. Your recommendations (and private comments) to the editors can be as blunt as you want.

- Recognize that your review comments on papers that we reject at JAMS are not wasted; they improve the quality of the paper wherever it is eventually published.

\section{Conclusion}

As a reviewer for JAMS, try to not see your primary role as screener or gate-keeper. Instead, reconceive your role as "developmental coach," taking the opportunity to help authors find their voice. Provide guidance on how to pare away, refine, and improve aspects of authors' early drafts that are distracting, poorly executed, poorly fitting, or even flat-out wrong. Doing so will insure that papers published in JAMS are of the highest quality. We summarize our proposed action steps in Table 1. Even if the paper you review cannot reach the standards for being published in JAMS, you can take pride in having made an important contribution to the quality of work in our field and to the scholarly development of the author.

\section{References}

Bagchi, R., Block, L., Rebecca, W., Hamilton, R. W., Julie, L., \& Ozanne, J. L. (2017). A field guide for the review process: writing and responding to peer reviews. Journal of Consumer Research, 43(5), 860-872.

Houston, M. B. (2019). Four facets of rigor. Journal of the Academy of Marketing Science, 47, 570-573.

Kumar, V. (2016). My reflections on publishing in Journal of Marketing. Journal of Marketing, 80 (1), 1-6.

Lehmann, D. R., \& Winer, R. S. (2017). The role and impact of reviewers on the marketing discipline. Journal of the Academy of Marketing Science, 45, 587-592.

Moorman, C., van Heerde, H., Moreau, C.P., \& Palmatier, R.W. (2019). Managing the review process at Journal of Marketing. Accessed September 10, 2020, https://www.ama.org/wp-content/uploads/ 2019/11/Managing-the-Review-Process-at-the-Journal-ofMarketing-Final.pdf

Saunders, C. (2005). Editor's comments: Looking for diamond cutters. MIS Quarterly, 29(1), iii-viii.

Stetson, N. (2019). Capturing the creative process in "Songland." Florida Weekly, July 3. Accessed September 10, 2020, https://fortmyers. floridaweekly.com/articles/capturing-the-creative-process-insongland/

Publisher's note Springer Nature remains neutral with regard to jurisdictional claims in published maps and institutional affiliations. 